\title{
Desejo e prazer: um aspecto da sexualidade entre os Karitiana
}

\author{
Andréa Oliveira Castro \\ Universidade Federal do Paraná, Curitiba, Paraná, Brasil
}

DOI 10.11606/issn.2316-9133.v24i24p505-523

resumo A proposta do presente artigo é analisar um dos muitos aspectos da sexualidade Karitiana, grupo Tupi Arikém de Rondônia, através de suas conexóes a outras instâncias da vida social do grupo. A partir de sua relação com diferentes campos - a saber, a mitologia, a dinâmica dos corpos, as emoçóes e as sensaçóes -, é possível perceber que desejo e prazer sexual, ao serem conectados a essas outras esferas, ganham destaque no processo de produção de pessoas, na arquitetura da sociabilidade e na própria possibilidade de existência da sociedade.

palavras-chave Karitiana; Sexualidade; Pessoa; Parentesco; Emoções.

\section{Desire and pleasure: one aspect of sexuality among the Karitiana}

abstract This article intends to analyze one out of many aspects of the sexual life among the Karitiana, a Tupi Arikem indigenous group, looking at its connections with other instances of the group social life. From its relation to different fields - namely, mythology, bodies' dynamics, emotions and sensations -, it is possible to perceive that, when connected to these other spheres, sexual desire and pleasure assume a privileged position in the process of the fabrication of people, in the architecture of sociability, and even in making possible the very existence of society itself.

keywords Karitiana; Sexuality; Personhood; Kinship; Emotions. 


\section{Antropologia e sexualidade: um breve panorama}

Como alguns autores já mostraram (VANCE, 1995; ALMEIDA, 2003; entre outros), a sexualidade não ocidental tem sido, de uma forma ou de outra, objeto de interesse da antropologia desde o começo da disciplina. Contudo, as luzes lançadas sobre o tema sofreram as difraçóes peculiares às perspectivas teóricas assumidas por quem o olhava, resultando no fato de que a atenção não fora destinada à sua compreensão e de seus significados específicos, mas, antes, ao lugar ocupado pela sexualidade como fundamento de tipos de instituição ou ao seu lugar na articulação das relaçóes de outras esferas da vida social, confinando a vida sexual de outros povos a uma posiçáo subsidiária de outros ordenamentos.

Assim, durante o evolucionismo, a sexualidade, entendida como manifestação do instinto básico universal (cf. ALMEIDA, 2003) da sobrevivência e perpetuação da espécie é radicalmente oposta à razão e assumida como sinal diacrítico da capacidade mental dos povos, além de ser associada diretamente à fertilidade. Sociedades que, em função de seu ainda prematuro estágio intelectual, desconhecessem as "verdades" (ocidentais) que vinculavam relaçóes sexuais aos princípios de paternidade e que, por isso, conformariam "sociedades promíscuas", engendravam conformaçóes sociais nas quais outras instituições, como o totemismo, o sistema de parentesco e a propriedade, eram a prova cabal do tipo de razão, prática sexual e moralidade nelas existentes. Necessariamente, a evolução de uma implicaria na evolução das outras, de modo que e a sexualidade e suas práticas viriam, um dia, a se moralizar como decorrência do descortinamento da razão. Tomada como instinto, a sexualidade era o oposto da razão, e tais povos primitivos eram por ele comandados. Apenas a escalada da razão e o processo civilizatório poderiam controlar tais instintos

A primeira metade do século XX traria não mais uma oposição entre instinto (no caso, a sexualidade) e razão, mas aquela que capitaneará as abordagens do período: entre indivíduo e cultura. Nesse momento, procede-se uma desvinculação da sexualidade das práticas sexuais e a introdução das categorias analíticas de gênero, emoçóes e indivíduo. Nesse modelo de influência cultural (cf. VANCE, 1995), no qual teremos Malinowski (1973 [1927]; 1983 [1929]) e Mead (1971 [1928]; 1972 [1935]) como principais expoentes, a cultura é responsável pela modelagem da expressão e dos costumes sexuais, mas o fundamento da sexualidade - agora tratada como "pulsão" ou "impulso" - continuaria ainda entendido como universal e naturalmente dado, e a sexualidade ainda determinada pelo princípio reprodutivo. 
Enquanto dado natural básico da humanidade, fosse como pulsão ou atributo biológico, caberia à cultura moldá-lo e normatizar e regular suas práticas, ficando as sensaçóes circunscritas ao íntimo dos indivíduos ou ao gênero adscrito pela sociedade. Malinowski e Mead partem do entendimento dos indivíduos como entidades autônomas, dotadas de instintos, portadores de um corpo tomado como substrato natural e diferentemente sexuado sobre o qual a cultura sobrepóe a divisão de gênero, de trabalho e das emoções e, consequentemente, da sexualidade, com o intuito de viabilizar a sociedade humana. Assim, indivíduos, "naturais" em todos os aspectos, precedem logicamente a sociedade que, por sua vez, se valeria deles para sua própria formação.

Lévi-Strauss, entendendo a sexualidade como o "único instinto humano que depende do estímulo de outro" (LÉVI-STRAUSS, 1982, p. 50), argumentará que será sobre ela que recairá a primeira regra que instauraria a passagem de um suposto estado de natureza a um estado de cultura, motivada, acima de tudo, por um imperativo da vida social, a troca. A oposiçáo, agora, entre natureza e cultura, tem como operador lógico o regramento da sexualidade, esta tomada como dado, indubitavelmente biológico (ou natural), sobre o qual, não apenas a cultura se inscreve, mas dele se vale para desenhar sua geometria social, como atestado no modelo estruturalista do parentesco.

No estruturalismo, a sexualidade é desdobrada em dois níveis: o vivido, no qual a sexualidade é instrumento de diferentes categorias envolvidas na troca, e o pensado, expresso pela percepção lévi-straussiana da sexualidade no nível mitológico (LÉVI-STRAUSS, 2004-2011): a forma como as categorias, atitudes e desejos, metaforicamente tomados, são conectados a inúmeras outras variáveis sociais. Aqui, a sexualidade, apesar de ainda ser tomada como natural, é submetida ao entendimento de seu lugar lógico nas relaçóes sociais, mas sempre, em ambos os casos, subsumida à oposição entre natureza e cultura.

\section{A sexualidade no contexto ameríndio}

A etnologia ameríndia, no que concerne à sexualidade, seguiu à risca a agenda da antropologia e pouco se dedicou à compreensão da vivência sexual dos povos amazônicos. Compassadamente à antropologia, vinculou o entendimento da sexualidade entre os grupos indígenas às investigaçóes de fertilidade, construção de gênero, divisão do trabalho etc., replicando as oposiçóes que a antropologia já havia pautado - tendo escapado da oposição entre razão e instinto, correu de encontro às entre indivíduo e cultura e natureza e cultura. 
A vinculação a tais entendimentos anteriores (a saber, a relação indivíduo-cultura e natureza-cultura) fez com que a sexualidade ameríndia fosse analisada em três ordens: psicológica, por aqueles que tivessem adotado a dicotomia entre indivíduo e cultura, e econômica e simbólica, por aqueles que tivessem seguido a bipartição estruturalista, sendo esta a abordagem de maior impacto na etnologia brasileira. Porém fracas luzes foram lançadas sobre o conteúdo erótico das relaçóes e as maneiras pelas quais o desejo e o prazer eram vividos e entendidos por tais grupos.

Orientada pelas abordagens estruturalistas, de ênfase econômica e simbólica, uma das primeiras empreitadas para se debater a sexualidade ameríndia tem lugar no simpósio ocorrido em 1982, que resulta na publicação de Sexual Ideologies in Lowland South America (Kensinger (ed.), Working Papers on South American Indians, 1984). O objetivo de tal simpósio era discutir as relaçóes entre sexo e comida, particularmente a troca de carne por sexo, em resposta ao trabalho de Holmberg (Nomads of the Long Bow, 1950) e Sisikind (To Hunt in the Morning, 1975), com o objetivo de examinar "sexo e sexualidade em várias sociedades tribais" (KENSINGER, 1984, p. iv).

O propósito do seminário já revela o sentido econômico dado à sexualidade, mas, apesar da proposta, o volume publicado é um exemplo de compilação dos três tipos de abordagem citadas acima. A maior parte dos artigos irá tomar a sexualidade como relaçóes entre os gêneros (cf. MENGET, para os Txicão; LANGDON, para os Siona) e relaçóes dos papéis de gênero nas esferas mitológica e ritual (cf. MENGET, para os Txicão; ARCAND, para os Cuiva; GREGOR, para os Mehinaku). Destaco que, da referida publicação, apenas os trabalhos de Chernela e Kensinger versam, embora de modo não muito aprofundado, sobre prazer e erotismo Unano e Cashinauhua, respectivamente.

Gow, em seu artigo "The Perverse Child", em diálogo com o Simpósio acima referido, faz também a equivalência entre os desejos sexual e por comida, salientando o fato de que tais desejos e os modos de satisfazê-los são os principais temas das conversas cotidianas piro (GOW, 1989, p. 567). Gow, contudo, também centra sua análise na divisão sexual do trabalho para a produção, circulação e consumo de comida sob o regime do parentesco e traça um interessante paralelo entre respeito e exigência (ou demanda - "demand" no original) e as possibilidades de intercurso sexual, no qual as pessoas que mantêm uma relação de respeito nada podem demandar uma da outra e o sexo, entre tais pessoas, é proibido. Inversamente, com quem se mantém uma relação de demanda, pode-se, também, ter uma relação na qual o sexo é permitido. 
Portanto, uma relação de demanda - entre adultos - é, inevitavelmente, uma relação sexual (GOW, 1989, p. 573) e um relacionamento conjugal consiste na satisfação da demanda por comida e sexo, marcando a diferença entre esposas e amantes e seus respectivos lugares na cadeia de produção. Gow observa que, entre os grupos amazônicos, o corpo e "seus desejos são de imediata significação social e a satisfação do desejo corporal é simultaneamente a criação de relaçôes sociais" (GOW, 1989, p. 581). Talvez, a melhor descrição sobre a sexualidade de um grupo ameríndio seja sobre os Canela (CROCKER, 1974; 1990). Ele nos informa sobre o investimento no prazer pelos Canela e sobre as práticas sexuais que, antes de um contato mais intenso com a sociedade nacional, atuavam como poderosos meios de construção de relaçóes sociais. Entretanto, as relaçôes sexuais permanecem entendidas pelo autor como articuladoras do sistema de metades e de um esquema econômico em que as mulheres prestam favores sexuais em troca de carne.

$\mathrm{Na}$ linha das abordagens psicanalíticas, o trabalho de Isacsson (1993) sobre os Emberá nos deixa com pouca margem para um entendimento mais profundo da sexualidade do grupo dada a dificuldade em distinguir o que é próprio ao pensamento Emberá e o que é interpretação do autor. De qualquer modo, o que importa notar é que este considera a sexualidade Emberá a partir dos níveis psicocosmológicos, sendo um o reflexo do outro, tentativa também feita por Gregor (1985) para os Mehinaku. Se desconsiderarmos sua análise psicológica, o trabalho de Gregor é denso no que diz respeito aos dados sobre aspectos eróticos e performáticos da sexualidade Mehinaku, que variam desde as posiçóes sexuais adotadas até os sonhos eróticos.

Uma abordagem de cunho mais simbólico, mas contendo também tintas psicológicas, já havia sido executada por Reichel-Dolmatoff (1971) para os Desana ao descrever as relaçóes entre Desana e Maku, nas quais os últimos não seriam apenas servos dos Desana, mas, também, seus objetos sexuais. Reichel-Dolmatoff versa sobre a repressão sexual e a ansiedade relacionada a tudo o que diz respeito a sexo no grupo. Dividindo o cosmos em elementos masculinos e femininos, Reichel-Dolmatoff percebe uma relação de complementaridade fertilizante, isto é, energia procreativa na qual a Via Láctea ocupa um lugar central, sendo equacionada a um "imenso fluxo seminal que fertiliza tudo que há abaixo dela"; a estrutura cosmológica e seu circuito de fertilização derivariam do modelo da sexualidade fisiológica. A potência feminina para o sexo é considerada maior que a dos homens, o que faz as crianças se parecerem mais com as mães. $\mathrm{O}$ modo Desana de estar no mundo é então interpretado através de uma cosmologia sexualizada e marcada pelo gênero. 
Condensando o que foi exposto, podemos afirmar que a sexualidade ameríndia tem sido analisada sob três diferentes ordens: a primeira, psicanalítica, enfatiza as possíveis correlaçóes entre o praticado no real e os estados psíquicos experimentados pelos indivíduos; a segunda, econômica, toma a troca de comida por sexo como ponto de partida e posiciona a sexualidade ameríndia como parte do sistema produtivo do grupo; e a terceira, simbólica, privilegia as ordens mitológicas e rituais, limitando-se a examinar a sexualidade em seu conteúdo metafórico. Erotismo, desejo e prazer assumem um lugar secundário, vinculados ou significados por outros processos sociais.

Como disse acima, Gow e Crocker afirmam que as "relaçôes sexuais criam relaçóes sociais"; mas, se li corretamente suas argumentaçóes e os dados apresentados, as relações sexuais são entendidas antes como consequentes de, ou subordinadas a, processos outros, e não elas mesmas como princípios ordenadores: em Gow, as relaçóes sexuais e o desejo são equacionados à economia das trocas e subsidiárias da sociabilidade, em Crocker, um sistema de oposiçóes de metades e gêneros comanda a atividade sexual canela.

Tudo permanece como se os aspectos eróticos da sexualidade não possuíssem, em si mesmos, o poder de criar significados e tivessem os que a ela são atribuídos derivados de outros campos mais nobres, excluindo assim o prazer e o desejo das possibilidades de produção de significaçóes para outros campos da vida social. O objetivo do presente trabalho é apresentar os dados sobre um dos aspectos da vida sexual dos Karitiana, tema, tal como já observara Gow para os Piro (Gow, 1989), também constante em seu cotidiano. Todavia, a etnologia ameríndia se encontra em um momento teórico diferente daqueles apontados no começo desse texto.

Valendo-se da (já agora longa) trajetória de discussão da noção de pessoa e da centralidade do corpo para esses grupos, iniciada na década de 1979 (SEEGER; DA MATTA; VIVEIROS DE CASTRO, 1979) e, de lá para cá, se beneficiando de um aumento significativo de descrições etnográficas, culminando, mais recentemente, no(s) perspectivismo(s) ameríndio(s) que revela $(m)$ metafísicas diferentes para os grupos do continente (VIVEIROS DE CASTRO, 1996; STOLZE, 1996); usufruindo do atual quadro teórico da antropologia, no qual as dicotomias mente/corpo, natureza/cultura, indivíduo/sociedade, sujeito/objeto, razão/emoção (ou instinto) perdem sua saliência, uma vez que os campos não são mais entendidos como instâncias absolutas e dá-se lugar às múltiplas possibilidades de conexão e aos variados contextos (cf. STRATHERN, 1992; 2004) e aos conceitos particulares a cada grupo (VIVEIROS DE CASTRO, 2015), a disciplina ampliou largamente as possibilidades de leitura dessas outras realidades. 
Tal panorama favorece o reordenamento das posiçóes anteriormente conferidas às diversas esferas da vida social desses grupos e, desse modo, trato aqui de tentar entender parte da sexualidade karitiana não mais como subsidiária de outros ordenamentos opositivos considerados maiores. Contrariamente, parto das percepçóes e do esquema conceitual do próprio grupo para examinar a conexão de aspectos de sua vida sexual com outras instâncias da vida social - como a mitologia, a dinâmica dos corpos, as emoçóes e sensações -, na esperança de poder demonstrar que desejo e prazer sexual, ao serem conectados a essas outras esferas, ganham destaque no processo de produção de pessoas, na arquitetura da sociabilidade e na própria possibilidade da existência da sociedade. De modo que, nessa outra escala, a posiçáo de subordinaçáo antes ocupada pela sexualidade - e, em especial, o desejo e o gozo - parece se inverter, e a sexualidade surge qualificada como potência ordenativa privilegiada na tessitura do socius.

\section{Desejo e gozo entre os Karitiana}

Como dito acima, Gow e Crocker propóem que "relações sexuais criam relações sociais"; o que o material karitiana parece apontar é que, além de criar relaçôes sociais, o desejo sexual e sua satisfação são significantes da noção de sociedade e deles derivam significados sociais relevantes, pois arquitetam as condiçóes e os modos de os Karitiana estarem no mundo. Se em outras etnografias sobre os grupos ameríndios a sexualidade parece ser entendida como posterior à sociedade ou infletida por outras ordens da vida social, entre os Karitiana ela aparece reposicionada, como anterior e como condição de formação da mesma. Se, como diria Vance (1985), o "interessante em uma pesquisa sobre sexualidade é mapear o que é culturalmente possível", entre os Karitiana, ao que parece, só existe o "culturalmente possível" se sexualmente desejável. E não falo aqui de uma suposta faculdade reprodutiva universal da espécie humana como já quis a concepção ocidental, mas, antes, de um entendimento nativo que assume o desejo sexual, o prazer e os modos de sentir como condiçóes de possibilidade de existência da sociedade e da sociabilidade. Vejamos.

Primeiramente é preciso definir o que está sendo tomado como "sexualidade karitiana" no presente trabalho. Certamente, seria inapropriado trasladar o conceito de sexualidade das sociedades ocidentais - e tudo o que ele implica - para outras sociedades que não partilhem, sequer, de um único termo que abranja tudo aquilo que entendemos por sexualidade e suas práticas, como é o caso karitiana. De modo que a pergunta o que é considerado sexual para os Karitiana? precisa, antes de mais nada, ser respondida. E, definitivamente, para um Karitiana, o desejo sexual não é igual 
ao desejo por comida, como entre os Piro. Certa vez, perguntado o que era o desejo sexual, um Karitiana me respondeu:

[Antropóloga:] Mas, o que é o desejo? Como a gente sabe que está com tesão?

[Karitiana:] Quando você come uma comida boa, você treme? [Antropóloga:] Não!

[Karitiana:] Quando você bebe chicha boa, você treme?

[Antropóloga:] Não!

[Karitiana:] Então! Só mulher faz a gente tremer! Você não treme não quando tá querendo seu namorado? Sabe quando a gente não aguenta mais? Quando já tá de um jeito que tem que pegar? Tá quase ficando doido? Fica querendo o tempo todo. A gente não aguenta dentro da gente não! Tem que fazer logo! [fazendo gesto do ato de penetrar, de efetivamente transar.]

Para os Karitiana, o desejo sexual não se compara a nenhum outro, assim como a sensação experimentada pelo gozo é incomparável a qualquer outra. Para o que interessa aqui neste trabalho, resumidamente, está se tomando como sexual o que o grupo entende que seja uma relaçáo de cunho sexual: contato íntimo e diferenciado - pois não é o mesmo que se tem com todo mundo - com outra pessoa (o sexo individual - masturbaçáo - não será tratado aqui) a qual se deseja "sentir" a pele, o toque, o cheiro; motivado pelo desejo que toma o sujeito em todo o seu ser e altera seu estado corporal e mental de tal modo que se tem vontade "de quase engolir a pessoa", "até a baba [de água na boca; babar] da gente quer a pessoa"; que faz com que a pessoa não pense em mais nada a não ser em "brincar" com a outra e gozar, "morrer um pouco no outro". O gozo muitas vezes foi descrito como "quase a gente morre", 1 "tira tudo que tem dentro da gente" [no sentido de retirar os males do corpo], "não tem coisa melhor na vida".

Únicos falantes do Tupi Arikém, os Karitiana, povo indígena da região de Rondônia, somam hoje cerca de quatrocentos indivíduos. Apesar de existirem várias outras expressóes e detalhes da vida sexual Karitiana (como o significado dos casos extraconjugais, do incesto e da masturbação, da homossexualidade, das novas perspectivas sexuais advindas das relaçóes com a sociedade envolvente, a relação entre sexualidade e divindade, posições sexuais e remédios como agentes na produção do dimorfismo sexual; certamente, também a dimensão econômica traduzida pela troca de comida por sexo etc.), que também se conectam a outros aspectos da vida social do grupo (como a dispersão pelo território, processos toponímicos, alteraçóes 
na grade de parentesco, acusaçóes de feitiçaria, cisóes e rupturas do grupo e uma série de outros acontecimentos da vida karitiana), a presente exposição se restringirá à face da sexualidade do grupo na qual o desejo e o prazer surgem como potências dos seres e condiçôes imprescindíveis no processo de produção de pessoas.

Em geral, os homens falam sem muitas restriçóes sobre aspectos de sua vida sexual e, muitas vezes, com tons de vanglória. Um homem Karitiana não passa, diz-se, um dia sem sexo. De acordo com os mesmos, homem sempre quer sexo, e tanto melhor se forem várias vezes ao dia. Um homem que só consegue manter uma relação por dia é motivo de pena e logo se corre para providenciar remédios que lhe aumentem a potência. Os rituais e situaçóes que demandam abstinência sexual são considerados penosíssimos e difíceis de serem mantidos por eles. Quase todos os homens têm seus órgãos apelidados, geralmente por outros homens, em função de suas aventuras (ou desventuras) sexuais. Os solteiros, os envolvidos em casos extraconjugais ou namorados secretos estão, quase sempre, maquinando suas próximas investidas e as estratégias para conseguir uma relação sexual. Se um homem casado se retira de uma roda de conversa, uma das primeiras justificativas para sua saída que vêm à mente dos remanescentes, seja em tom de brincadeira ou não, é "ah, ele tá com desejo" ( $i$ pysso akyn i).

Por outro lado, as mulheres náo são tão loquazes quanto eles no que se refere a sua vivência sexual. Embora brinquem muito umas com as outras a respeito de suas vaginas e confidenciem desejos e casos amorosos, isso é feito em grupos mais restritos de irmãs ou parentas próximas. De acordo com elas (e com eles também) "só os homens pensam e querem sexo, e mulher nunca quer" e náo cabe a elas procurarem seus maridos para o sexo ou manifestarem seu desejo. Diante disso, poderíamos supor que eles estariam sempre atrás de sexo, ao passo que elas estariam sempre a fugir do sexo.

À primeira vista, poderíamos rapidamente concluir que não há prazer feminino no ato sexual, e que as mulheres Karitiana seriam apenas objeto de seus maridos e controladas por eles no plano sexual. Contudo, uma aproximação mais demorada revela que não se passa um dia sem que elas também não falem, entre elas, em sexo, reclamem do desempenho de seus maridos, brinquem sobre sexo ou se penalizem de uma mulher sozinha: "mas, você não tem ninguém nem para te molhar um pouquinho?". E, descobre-se que elas também não querem ficar sem sexo.

É tão impossível se manter sem sexo, na visão karitiana, sejam homens ou mulheres, que a descrença em relaçáo aos votos de abstinência dos missionários católicos, por exemplo, circula profusamente na aldeia e é motivo de várias piadas. Uma pessoa sem fazer sexo é motivo de lamentação (ou, no caso dos missionários, é certamente mentira, pois é lógico que o "padre 
come a freira"), algo tem de ser feito porque, sem sexo, ninguém pode ficar, seja homem ou mulher. A falta de sexo causa envelhecimento, faz enrugar rapidamente, fica-se feio e se adoece. E, a partir daí, descortina-se um outro universo no qual o prazer feminino assume um lugar central.

Tempos atrás, as mulheres não tinham filhos. Ninguém gerava filhos. Só Botyj, divindade karitiana criadora da primeira humanidade, era quem produzia as famílias, manufaturava as crianças e as entregava aos pais. As mulheres também não menstruavam. Isso, antes de Lua. Assim como em outros grupos Tupi e outros grupos da região amazônica (cf. LÉVI-STRAUSS, 2004-2011; BELAUNDE, 2005, entre outros), Lua mantém, solertemente, relações sexuais com sua irmã, tem sua face manchada de jenipapo e, depois de forçar uma relaçáo sexual com sua mãe, sobe aos céus. Ao subir, informa a sua mãe que, a partir daquele momento, as mulheres iriam sangrar. E iriam sangrar porque ele, assenhorando-se de todas elas e desejando-as fortemente, manteria periodicamente relaçóes com elas.

De acordo com os Karitiana, mulher que não menstrua não pode engravidar. Todavia, a própria menstruaçáo e, portanto, a capacidade reprodutiva feminina, advém de um desejo: em virtude de sua incontrolável lascívia, Lua vem, invisivelmente, todos os meses, manter relaçóes sexuais com as mulheres. A menstruação é evidência de que ocorreu a relação sexual com Lua, pois que é percebida como "esperma de Lua". ${ }^{2}$ Assim, em tempos primórdios, o desejo excessivo de Lua - o incesto com a irmá e a máe - garantem a primeira possibilidade de os humanos se apropriarem do processo de produçáo de pessoas, através da menstruaçáo, retirando da divindade sua prerrogativa. Além disso, na vida atual, são o desejo e o gozo periódicos de Lua, isto é, seu coito mensal com as mulheres, com a consequente vertida de seu sanguíneo esperma - menstruação -, que possibilitam às mulheres adquirirem e manterem a capacidade de gerar filhos.

Lua gosta de mulheres novas e mantém por elas um desejo ardente e constante. À medida que os anos passam e que seus corpos envelhecem, deixam de ser sexualmente atraentes para Lua, e ele não mais as deseja, suspendendo as relaçóes sexuais com elas. Consequentemente, elas perdem sua capacidade reprodutiva: não mais menstruam e seus úteros ficam "secos", ou seja, a menopausa é percebida como decorrente da inapetência sexual de Lua pelas mulheres. Dizem os Karitiana que Lua mantém relaçóes com as mulheres para lhes dar força e saúde. Se Lua não mantém relaçóes com elas e, caso não lhes ocorra a menstruaçáo, a mulher terá dores de cabeça, mal-estares e ficará com o corpo sujo, sendo, portanto, o desejo de Lua que as mantém saudáveis, úmidas e férteis. Todavia, as mulheres não sentem prazer na relação com Lua, pois nem mesmo "sentem que estáo tendo relação com Lua", dada a invisibilidade dele. 
Através de casamentos arranjados (prometidos) pelos pais, as meninas se casavam por volta dos 9, 11 anos - atualmente, um pouco mais tarde e, sem a necessidade de esperar a primeira menstruação, já podiam iniciar a vida sexual com o marido, não havendo, dessa forma, a associação direta e contínua entre a relação sexual de um casal e a relação sexual com Lua. No passado, dizem, todas as mulheres casavam virgens e, ainda hoje, a virgindade é um valor para os Karitiana. Atualmente, os casamentos prometidos pelos pais vigoram entre os Karitiana; contudo, caminham pari passu com iniciativas dos jovens em querer escolher seus parceiros em razão de sentimentos experimentados, como amor e desejo, o que gera alguns problemas, pois, muitas vezes, jovens "apaixonados" por alguém e prometidos a outros devem manter e honrar o acordo formalizado pelos pais e casar mesmo, como dizem, "forçado".

De acordo com eles, uma mulher náo esquece o homem que "a formou" (nakam at, literalmente, "fazer") e irá, para sempre, pensar nele. Do mesmo modo, os homens não esquecem as mulheres com as quais mantiveram relaçóes sexuais. A lembrança de relaçóes passadas, do corpo do(a) outro(a), do prazer sentido com o(a) outro(a), fazem com que a memória náo se caracterize apenas como uma atividade do pensamento com respeito a acontecimentos passados, mas também como um dispositivo de experimentação corporal capaz de manter as sensações corporais passadas vivas no presente, de tal modo que lembranças e sensaçóes corporais, nesse caso, se tornam uma só experimentação. Quanto mais intensa for a relação e mais intenso o prazer, mais forte também serão as lembranças, sensações corporais e, consequentemente, o vínculo com o outro(a).

Motivo de muitos ciúmes, a memória de relações sexuais prévias não se apaga facilmente, podendo demorar muitos anos a se dirimir e, dependendo da força do vínculo, pode até mesmo ser indelével. Além da compreensão karitiana de que os homens adquirem certo direito sobre as mulheres que formaram e que os autoriza a provocá-las, mesmo que não estejam mais com eles e fora das vistas dos atuais cônjuges, há outro fator. Uma vez que um casal manteve relaçóes, poderão estar fadados, por conta de uma eterna lembrança e vividez corporal, a sempre querer novamente e, a qualquer momento, um poderá ceder ao outro.

Relações sexuais e sua lembrança possuem o poder de escrever biografias afetivas e criar vínculos emocionais, pois uma relação sexual entre os membros do grupo quase nunca é vista como passageira, diferindo das relaçôes sexuais que mantêm com os brancos na cidade, ${ }^{3}$ essas últimas de caráter mais esporádico, sem uma necessária continuidade e constância de parceiro, podendo ser em troca de pagamento ou presentes. Tais relaçóes também são referidas como "relação para apagar a memória”, "apenas para 
aliviar a vontade", significando que elas não se inscrevem - ou não deveriam se inscrever - no sujeito, e poucas ficam na lembrança afetiva, sendo registradas mais como exemplos de brincadeira, experiência e acúmulo de conhecimento sobre a alteridade. Assim, a virgindade é também, entre outras coisas, um seguro contra traiçōes futuras, pois ela garante que a mulher vai aprender a só gostar do marido, a só "sentir com ele".

Segundo os Karitiana, uma mulher que se casa ainda virgem demora cerca de um ano para engravidar; contrariamente, uma mulher que já teve muitas relaçôes antes de casar engravidará rápido. Tal temporalidade diferenciada é explicada pelo processo pelo qual passa a mulher para "aprender a sentir". Enquanto a que nunca teve relaçóes precisará de tempo para aprender a sentir prazer, a que já manteve várias relaçôes sexuais já "sabe como sentir".

No início da vida sexual, pelo fato de a mulher ainda não ter aprendido a sentir prazer, o homem deve proceder com calma, estudando o jeito da mulher, estudando seu corpo, os locais em que ela é mais sensível, de modo que ele possa fazê-la "se soltar". Os homens são mesmo capazes de descrever como sentem o interior da vagina feminina, as peculiaridades de cada uma e em que lugar uma determinada mulher sente mais, e tanto homens quanto mulheres dizem que "cada um sente de um jeito", não sendo as pessoas iguais; a cada relação, um reaprendizado do outro. Até lá, não há problema se o homem "soltar seu esperma" e a mulher não; de qualquer modo, ainda assim ele deve se controlar para poder aguentar "fazer o máximo de carinho possível nela".

Dizem que a menina, no princípio da vida sexual, "tem medo", ainda não aprendeu "o jeito do homem" e "como são as coisas". A vagina, ainda dura, deve ser amolecida pelo homem para que a mulher comece a sentir prazer. Um Karitiana jamais pode "furar de qualquer jeito a menina", um homem assim é tido como irresponsável e que "não cuida da sua mulher", no sentido de que "não liga para o que ela sente". Não se pode machucar a mulher. Ele deve ir, portanto, com calma, para náo provocar dores e, aos poucos, fazê-la relaxar, começar a gostar, podendo começar a acariciá-la com os dedos, explorando a vulva e as redondezas do clitóris, e iniciar assim o amolecimento da vagina, começando a introduzir um dedo, depois dois, preparando-a para a penetração.

Durante a interação sexual, a troca de suores, a absorçáo do cheiro de um no corpo do outro, os aproxima. Os cheiros do parceiro e do sexo mantido ficam impregnados no corpo, alterando o que era a pessoa antes da vida sexual, e ela passa a comportar, em si, a relaçáo com o outro, formando o casal. Náo que a impregnaçáo do cheiro promova um processo de assemelhamento entre o par, mas, antes, atua como elemento conjuntivo, vincula um ao 
outro. Nada impregna mais o cheiro do outro do que a relação sexual; além de ser o primeiro sinal inspecionado e percebido por um cônjuge ciumento, seja homem ou mulher, é motivo de grande perigo para lactentes se o pai se envolve em um caso extraconjugal no período em que sua mulher amamenta seu filho. A poliginia karitiana é sororal e, uma vez que as irmãs são vistas como "iguais", no caso de uma dar à luz, o marido pode, sem maiores riscos, manter relaçôes com a outra, pois os cheiros "são iguais".

A partir do momento em que as mulheres aprenderam a sentir prazer, os homens não devem mais "gozar primeiro" ou "gozar logo, rápido", pois, como dizem os Karitiana, a mulher tem mais resistência que o homem e demora um pouco mais a sentir prazer. Para que a mulher Karitiana "libere seu líquido", deve haver um investimento masculino na conquista do prazer feminino. A calma e a lentidão dos movimentos masculinos, fazendo a mulher ir "sentindo devagar", "ela sentir aquilo crescendo dentro dela", "até ela não aguentar e soltar todo seu líquido" e o controle masculino para gozar ao mesmo tempo que a mulher, são cruciais no momento da relação sexual. Caso o homem se satisfaça logo e não se empenhe em fazer a "mulher sentir", ela não irá mais gostar (e diminuirá o desejo) de manter relaçóes com ele, pois que ele "se solta logo" enquanto "ela nem começou a fazer o gosto dela". Ela precisa "se gastar", isto é, transvazar, sentir seu corpo todo "mexendo" durante a relação sexual para ficar bonita, para mudar o corpo e renovar a pele.

O desgaste masculino promovido pelo gozo é percebido como mais intenso, e do qual é mais difícil se recuperar (estar pronto novamente para outra relação), que o feminino, portanto, o homem deve reservar para o final o seu desgaste extravasado no gozo. Os prazeres feminino e masculino são entendidos como fatores de renovaçáo e fonte de juventude e, de uma pessoa ainda nova que cessou de manter relaçóes sexuais, se diz que "vai envelhecer logo", “vai ficar doente”, “já tá cabeça doida”. Ninguém deve ficar sem um parceiro por muito tempo, e aqueles que enviúvam, por exemplo, mesmo as mulheres, após um período de luto não muito extenso, já devem se casar novamente. Do mesmo modo que a relação de Lua com a mulher é crucial para a saúde feminina, a relação sexual do casal é necessária para a saúde de ambos.

Mas, mais do que isso, caso o casal não mantenha relaçóes sexuais prazerosas diárias, eles não engravidarão. Não raro, tanto homens quanto mulheres podem dizer que é o "esperma do homem que produz o filho na mulher", que "o filho é do homem". Na articulação de determinadas esferas, como a do parentesco e da onomástica - na qual uma lógica de transmissão de substâncias de pais para filhos os faz compor um grupo de pessoas que guarda semelhanças entre si, e um sistema de transmissão de nomes de avós 
paternos para filhos dos filhos homens (SC) faz equivaler geraçóes alternadas, ambos exibindo o entendimento de uma filiação patrilinear -, tais afirmações são plenas de sentido. Todavia, não excluem outras percepçóes que se revelam quando conectamos esses campos, parentesco e produção de pessoas a outro: o do erotismo.

De acordo com o grupo, a fecundação só é possível se, durante um mesmo ato sexual, o homem e a mulher liberarem seus respectivos líquidos decorrentes do prazer de ambos; não ocorrendo quando liberam seus líquidos em eventos sexuais diferentes. Tanto o líquido feminino quanto o masculino possuem o mesmo termo, it (esperma), acrescentado o gênero: jongsó it (líquido feminino) e tasso it (líquido masculino), líquidos que só são liberados durante a atividade sexual. Referências semelhantes ao protagonismo do "líquido feminino" são descritas por Azevedo (2009) para as mulheres de lauaraetê e Junqueira \& Pagliaro (2009) para os Kamayurá:

As mulheres de Iauaretê relataram que o feto é formado pela junção do wahsó feminino, traduzido como o óvulo ou um fluído expelido pelas mulheres durante a relação sexual com o wahsó ou esperma masculino [...]. O feto é formado aos poucos, pela união do wahsó (sêmen) masculino com o wahsó feminino [...], uma substância gelatinosa produzida durante o orgasmo feminino. (AZEVEDO, 2009, p. 468-471)

Informantes mais velhos [Kamayurá] explicam que a fecundação ocorre quando o sêmen se mistura ao líquido que lubrifica a vagina. (JUNQUEIRA; PAGLIARO, 2009, p. 457-458).

Por sua vez, os homens devem sentir um intenso desejo por suas mulheres, e todos os dias "transar" com elas "com muita vontade", "não é querer pouquinho não! Tem que querer muito", caso contrário, não conseguirá engravidar sua mulher. Mas isso náo significa que o casal deva sentir prazer na mesma intensidade ou do mesmo modo. Náo apenas não se sente prazer em todas as relaçóes sexuais, como também nem sempre se sente com a mesma intensidade. Há casais em que os homens sentem mais do que as mulheres, mas o que náo pode acontecer é que nada seja sentido por elas durante o ato. Duas mulheres, uma que só tinha um filho, e outra, dois, diziam que "não sentiam nada com os maridos, só sentiram poucas vezes", justificando assim suas reduzidas proles. O que não é possível é a mulher nunca sentir.

Um homem casado com duas mulheres não pode jamais manifestar maior desejo, isto é, gostar de transar mais com uma delas do que com a 
outra, ou "gozar mais vezes com uma do que com outra" e, caso o faça, a briga é séria e, nesse caso, elas podem demandar sexo. Ele deve atender as duas igualmente e garantir o mesmo número de orgasmos tanto com uma quanto com a outra. Caso contrário, pode ser acusado de não querer filhos com ela. De um casal que só possuía um filho, dizia-se: "ele só quer a piriquita dela, não tá querendo mesmo, não". Não existe aborto espontâneo entre os Karitiana, se uma mulher perde o filho, ela "tirou criança", "deixou cair criança”. E isso acontece ou quando a mulher não está satisfeita com o marido, "não o sente mais", quando não gosta mais dele ou ele não a trata bem. Caso a mulher sinta raiva do marido, a criança pode nascer com problemas (uma das formas como explicam o fato de algumas crianças nascerem com qualquer tipo de deficiência). Assim, o não prazer sexual e o não desfrutar de uma convivência de afeto inviabiliza a sociedade, não apenas no plano da sociabilidade, mas, também, no plano da existência física e concreta viável. Quando me refiro ao afeto não me remeto a um princípio moral da sociabilidade, mas antes a um estado afetivo, interno, experimentado pelos sujeitos.

Se, na relação com Lua as mulheres são objeto de desejo, não sentindo qualquer desejo ou prazer na relaçáo com ele, nem mesmo sentindo que estão sendo "comidas", ocupando uma posição passiva na qual não há a menor relevância em sua participação através do desejo ou prazer, essa relação, entretanto, as capacita a produzir filhos. $\mathrm{Na}$ relação com os homens, contrariamente, espera-se que ambos, homem e mulher, sintam desejo (embora não manifesto pelas mulheres) e prazer. Assim, uma tríade de desejos e prazeres - Lua, homens e mulheres - torna-se fundamental para que a geração de uma nova pessoa seja possível.

O processo do casal karitiana - que envolve a mulher aprender a sentir prazer, o casal conhecer um ao outro, se embeber um do outro através do cheiro, manter o desejo intensificado, adequar o seu ritmo para que ambos gozem durante o mesmo ato sexual - os capacita a produzir um filho. Tudo se passa como se, entre os Karitiana, os desejos, masculino e feminino, qualificassem seus respectivos espermas para produzir os filhos. O oposto, uma relação sexual sem desejo e prazer intensos, com temporalidades de sensações descompassadas, isto é, um sentir e o outro não, podem até liberar líquidos, estéreis, todavia. De modo que há duas considerações a serem feitas sobre o processo karitiana de produção de pessoas que talvez possam servir para se pensar outras realidades ameríndias.

A primeira é que o prazer feminino é elevado a uma condição, no próprio processo de fabricação de pessoas, que parece contrariar o que, até então, supunha-se para grande parte dos grupos ameríndios, que a mulher seria apenas algo como um receptáculo para o sêmen masculino, sem qualquer 
papel de destaque anterior ao processo de desenvolvimento do feto no útero (do tipo sangue $=$ partes moles $/$ sêmem $=$ partes duras $)$. Entre os Karitiana, embora náo nominado, pois não há termo específico para ele, o prazer feminino é reconhecido, suposto e esperado. Tanto assim que, se uma mulher mantiver relaçôes com mais de um homem e engravidar, ela saberá quem é o pai, pois será aquele com quem ela mais sentiu prazer. Quando uma criança se parece muito com a mãe, diz-se em tom de brincadeira: "só a mãe gozou"; brincadeira porque seria o impossível, uma vez que a própria existência daquela criança é a evidência do gozo simultâneo do casal.

A segunda é que tampouco o esperma masculino (e o feminino) é substância inerte. Mesmo que muitas etnografias descrevam os diversos mecanismos e estratégias concebidos pelos grupos ameríndios no sentido de adquirir e envigorar o sêmen, tais processos são, em sua maioria, pensados como relaçôes e transformaçóes entre substâncias - e de substâncias em substâncias - e, uma vez constituído o esperma, nada além de lhe conferir espessura e potência é necessário para que ele se configure como substância ativa. O que o material karitiana nos mostra é que "nem só de substância vive o sêmen"; certamente, há também esse aspecto, e os Karitiana possuem vários modos de adquiri-la e incrementá-la. Contudo, mais do que disso, é necessário que as sensaçóes experimentadas pela pessoa, no caso o desejo, ative sua capacidade específica, alterando sua mera condição de substância e qualificando-a como eficiente no processo de produzir um filho.

O que vimos das poucas referências etnográficas ao desejo sexual ameríndio é que são, na quase totalidade, entendidas sob uma ótica econômica, psicanalítica ou simbólica. Ou seja, a sexualidade tratada como estruturada pela sociedade, posterior a ela e cumprindo um papel quase automático, no vínculo a outras instituições, de reprodução social, ordenada por outros princípios. O objetivo aqui foi o de tentar entender a sexualidade karitiana não segundo qualquer desses planos, mas a partir de uma perspectiva analítica de relacionar campos da vida social do grupo que têm sido, costumeiramente, deixados à margem pela etnologia. Dessa forma, o desejo e o prazer surgem viabilizando e ordenando a existência do grupo no mundo, e a sexualidade, principalmente, a necessidade do gozo como agente na produçáo do socius, como estruturante da sociedade e que, ao fim e ao cabo, retira a sexualidade do plano de fundo e a reposiciona no lugar de figura, assumindo o papel de engrenagem e ordenação do socius. Se podemos dizer que não há sociedades sem pessoas, entre os Karitiana, ao que parece, só há pessoas e, portanto, sociedade, se houver o desejo e sua satisfação. 


\section{Notas}

1. O "quase morrer" enquanto característica do gozo difere do "morrer um pouco" experimentado pelo excesso de bebida ou situaçóes de doença. Apesar de ambos remeterem à baixa atividade corporal e/ou perda de consciência, nos dois últimos casos, o "morrer um pouco" é quase sempre marcado negativamente, reportado com preocupação e como um sofrimento experimentado, pois refere-se a um estado de vulnerabilidade da pessoa que a pode fazer correr riscos e/ou que pode ser decorrente de perigos, os quais colocam em jogo a integridade da pessoa. É, de fato, uma possível morte. Já o "quase morrer" do gozo, ao contrário, é mencionado com ar galhofeiro e com alegria, pois indica o estado de lassidáo do corpo que se gastou e se limpou através do ato sexual, cuja consequência é a saúde e o aumento do vigor. É, nesse sentido, um renascimento, uma cura.

2. A partir dessa equação, menstruação/esperma de Lua, é possível entender por que o cheiro da menstruação é tão desaprovado pelos Karitiana. Ele pode ser entendido como o cheiro mesmo de uma relação sexual que, por sua vez, é tão repugnado pela divindade. É possível pensar que tal ojeriza divina decorra do roubo de que foi vítima.

3. Embora não seja objeto do presente artigo, vale notar que nos últimos anos tem havido uma mudança e aumento significativos nas relaçóes sexuais mantidas com os "brancos". Se antes tais relaçóes eram prerrogativa quase exclusivamente masculina, atualmente as mulheres Karitiana também têm se engajado nesse tipo de relação, mas de maneiras e com sentidos bem diferentes dos masculinos.

\section{Referências bibliográficas}

ALMEIDA, Miguel do Vale. Antropologia e sexualidade. Consensos e conflitos teóricos em perspectiva histórica. In: Fonseca, L.; Soares, C.; Vaz, J. M. (Org.). A sexologia, perspectiva multidisciplinar. v. 2, Coimbra: Quarteto, 2003. p. 53-72.

AZEVEDO, M. Saúde reprodutiva e mulheres indígenas do alto rio Negro. Caderno $C R H$, v. 22, n. 57, p. 463-477, set./dez. 2009.

BELAUNDE, L. E. El recuerdo de Luna. Género, sangre y memória entre los pueblos amazónicos. Lima: Fondo Editorial de la Facultad de Ciencias Sociales - UNMSM, 2005.

CROCKER, W. Extramarital Sexual Practices of the Rankokamekra-Canela Indians: an analysis of socio-cultural factors. In: Lyon, P. (Org.). Native South Americans: ethnology of the least known continent. Boston: Little, Brown and Co., 1974. p. 184-194. 
The Canela (Eastern Timbira), I: an ethnographic introduction. Washington: Smithsonian Intitution Press, 1990.

GOW, Peter. The Perverse Child: desire in a native Amazonian subsistence economy. Man N.S, 24. 1989.

GREGOR, T. Anxious Pleasures. The sexual lives of an Amazonian people. Chicago/Londres: The University of Chicago Press, 1985.

ISACSSON, Sven-Erik. Transformations of Eternity: on man and cosmos in Emberá thought. Göteborg, 1993. Dissertação (Doutorado) - Department of Social Anthropology, University of Göteborg.

JUNQUEIRA, C.; PAGLIARO, H. O saber kamaiurá sobre a saúde e o corpo. Caderno CRH, v. 22, n. 57, p. 451-461, set./dez. 2009.

KENSINGER, K. Sexual Ideologies in Lowland South America. Working papers on South American indians. July, Bennington College, Bennington, Vermont 1984.

LÉVI-STRAUSS, C. As estruturas elementares do parentesco. Petrópolis: Vozes, 1982.

Coleção Mitológicas. São Paulo: Cosac Naify, 2004-2011.

MALINOWSKI, B. Sexo e repressão na sociedade selvagem. Petrópolis: Vozes, 1973 [1927].

. A vida sexual dos selvagens. Rio de Janeiro: Francisco Alves, 1983 [1929].

MEAD, M. Coming of Age in Samoa. A sociological study of primitive society of western civilization. Nova York: William Morrow, 1971 [1928].

. Sexo e temperamento. São Paulo: Editora Perspectiva, 1972 [1935].

REICHEL-DOLMATOFF, G. Amazonian Cosmos. The sexual and religious symbolism of the Tukano indians. Chicago/Londres: The University of Chicago Press, 1971.

SEEGER, A.; DA MATTA, R.; VIVEIROS DE CASTRO, E. A construção da pessoa nas sociedades indígenas brasileiras. Boletim do Museu Nacional, 32. 1979.

STOLZE, Tania. Os dois e seu múltiplo: reflexões sobre o perspectivismo em uma cosmologia tupi. Mana Estudos de Antropologia Social/PPGAS/MN, v. 2, n. 2, out. 1996.

STRATHERN, M. After Nature. English kinship in the late twentieth century. Cambridge: Cambridge University Press, 1992.

. Partial Connections. Updated Edition. Altamira Press, Rowman \& Littlefield Publishers, Inc., Walnut Creek, Lanham, New York, Toronto, Oxford, 2005.

VANCE, C. A antropologia redescobre a sexualidade. Physis, Revista de Saúde Coletiva, v. 5, n. 1.1995.

VIVEIROS DE CASTRO, E. Os pronomes cosmológicos e o perspectivismo ameríndio. Mana Estudos de Antropologia SociallPPGAS/MN, v. 2, n. 2, out. 1996. . Metafísicas canibais. São Paulo: Cosac Naify, 2015. 
autora Andréa Oliveira Castro

É Mestre em Antropologia Social PPGAS/Museu Nacional/ UFRJ e Doutoranda na Universidade Federal de Juiz de Fora. Participa do grupo de pesquisa CNPQ Antropologia das Fronteiras Conceituais - UFJF. Professora Adjunta da Universidade Federal do Paraná na área de Antropologia, com ênfase em Etnologia Indígena.

Recebido em 10/12/2015

Aceito para publicação em 09/02/2016 